\begin{tabular}{|l|l|l|l|l|}
\hline Revista Jangwa Pana & ISSN: 1657-4923 & Vol. 14 & 148 - 159 & Enero - Diciembre de 2015 \\
\hline
\end{tabular}

\title{
OCIO, TRABAJO Y CULTURA: PERSPECTIVA DE REALIZACIÓN HUMANA
}

\section{LEISURE, WORK AND CULTURE: HUMAN PERFORMANCE PERSPECTIVE}

\author{
Manuel José Acebedo-Afanador ${ }^{1}$
}

\section{RESUMEN}

Se trata de hacer una sucinta reflexión, de carácter introductorio, sobre el sentido actual de la recreación, en el marco problemático del tiempo libre, el ocio y el trabajo. En los tiempos actuales, el tiempo libre ha adquirido una connotación que oscila entre la alienación, el aburrimiento y el consumo de cierta recreación prefabricada y costosa. Además, la recreación y el ocio han perdido su sentido por sí mismos, como actos liberadores y realizadores, y se han convertido solamente en tiempo de descanso al servicio del trabajo y del mercado de la diversión.

Palabras clave: Recreación; Cultura; Tiempo libre y ocio; Sociedad de consumo; Alteridad lúdica; Realización Humana.

\section{ABSTRACT}

It's about making a brief reflection, an introduction, on the current sense of recreation, problematic within leisure and entertainment. In modern times, free time has acquired a connotation of between alienation, boredom and consumption of certain recreational prefabricated and costly. In addition, recreation and leisure, have lost their sense of themselves as liberating and creative acts and have become only the service time off from work and market fun.

Keywords: Recreation; Culture; Leisure and entertainment; Alienation; Consumer society; playful otherness.

Tipología: Artículo de Reflexión

Fecha de recepción: 19/06/2015

Fecha de aceptación: 02/10/2015

Como citar este artículo: Acebedo-Afanador, M. (2015). Ocio, trabajo y cultura: perspectiva de realización humana. Jangwa Pana, 14, 148 - 159.

1. Magister de Evaluación en Educación. Doctorando en Currículo, Profesorado e Instituciones Educativas de la Universidad de Granada, España; docente-investigador del Departamento de Estudios Sociohumanísticos de la Universidad Autónoma de Bucaramanga de la Cátedra de la Escuela de Derecho en la Universidad Industrial de Santander, Colombia. Correo: macebedo@unab.edu.co 


\section{INTRODUCCIÓN}

"El infierno de los vivos no es algo que será; hay uno, es aquel que existe ya aqui, el infierno que habitamos todos los días, que formamos estando juntos. Dos maneras hay de no sufrirlo. La primera es fácil para muchos: aceptar el infierno y volverse parte de él hasta no verlo más. La segunda es peligrosa y exige atención y aprendizaje continuos: Buscar y saber reconocer quién y qué, en medio del infierno, o es infierno, y hacerlo durar y darle espacio" (Calvino, 2000, p. 70).

En la medida del tiempo construido históricamente, las palabras, los símbolos y sus significaciones cambian de muchas maneras, bien por su contenido moral, por su sentido práctico, por su uso o desuso, etc., usualmente ocurre en el lento decurso de las transformaciones culturales; pero hoy en día esta capacidad de cambio se ha transmutado a una velocidad tal que no alcanzamos a digerir un cambio cuando ya hay dos o tres más adelante, a veces ni siquiera nos enteramos de los cambios hasta que, por alguna razón, sorpresivamente nos damos cuenta que algo (objeto, símbolo, etc.) ya ha entrado en desuso, transformaciones que afectan el devenir cultural de los pueblos profundamente y con una celeridad jamás vistas que no permiten ni siquiera el asombro, sino solamente la levedad de lo velozmente pasajero y fútil al servicio del mercado.

Esta evolución es normal, deseable y necesaria; pero lo dramático aparece cuando el proceso se da porque el ser humano va asesinando, en una muerte lenta, su esencia como ser racional, espiritual y político; para dar paso a otro "ser humano" cuya esencialidad queda signada por la satisfacción de las necesidades bio- lógicas y económicas como fin de la vida misma -no es gratuito que la inmensa y profunda sabiduría indígena nos llame a nosotros, los de Occidente prepotente y civilizado, sus "hermanitos menores", por lo zafios, ignorantes e irresponsables-. Así la razón, como fundamento de la autonomía y de la libertad para la grandeza humana, se transforma en objeto de manipulación para la heteronomía y la esclavitud del consumo en la anónima mediocridad espiritual de la muchedumbre tecnificada, masificada e informe (Acebedo Afanador, 1995, p. 4)

Esta realidad dinámica y transformadora ha hecho que el sentido de la recreación (re-creación) haya cambiado en el mismo sentido en que la sociedad industrial ha generado nuevas relaciones sociales y nuevos sentidos en el tiempo libre, que ha aumentado cuantitativamente en algunas sociedades, pero cualitativamente parece que no tiene mucho desarrollo a pesar de las maravillas y de las fantasías programadas y prefabricadas.

Así, las ocupaciones humanas han terminado por tener cierto sentido de realización -felicidad- o de infelicidad, en relación con el trabajo, con la capacidad económica de satisfacer necesidades vitales y con su significado en entornos sociales altamente masificados y exacerbadamente consumistas; lo que conlleva a que el tiempo libre y el ocio no tengan significación autónoma, sino en relación de descanso con respecto al tiempo de trabajo o al consumo de "servicios de ocio". Incluso, además de la anterior, si el ser humano no se alcanza a realizar ni siquiera biológicamente en su pura animalidad, en sus necesidades vitales, menos va a encontrar su realización en los aspectos profundamente esenciales de lo humano: espiritual, intelectual, afectivo. Es la resignificación y actualización permanente del sentido marxista de la alienación: 
¿En qué consiste entonces la enajenación del trabajo? Primeramente en que el trabajo es externo al trabajador, es decir, no pertenece a su ser; en que en su trabajo, el trabajador no se afirma, sino que se niega; no se siente feliz, sino desgraciado; no desarrolla una libre energía física y espiritual, sino que mortifica su cuerpo, arruina su espíritu. Por eso el trabajador sólo se siente en sí fuera del trabajo, y en el trabajo, fuera de sí. Está en lo suyo cuando no trabaja y cuando trabaja no está en lo suyo. Su trabajo no es, así, voluntario, sino forzado, trabajo forzado. Por eso no es la satisfacción de una necesidad, sino solamente un medio para satisfacer las necesidades fuera del trabajo. Su carácter extraño se evidencia claramente en el hecho de que tan pronto como no existe una coacción física o de cualquier otro tipo se huye del trabajo como de la peste. El trabajo externo, el trabajo en que el hombre se enajena, es un trabajo de autosacrificio, de ascetismo... (Marx, 2005, p. 65)

La salvaje competencia del medio capitalista le impide su realización integral como ser humano a cambio de la apariencia y del consumo, que sólo se pueden sostener con el trabajo duro, así este trabajo no lo realice como ser humano sino que, al contrario, le impida crecer como persona y lo conduzca, a su vez, a la tragedia postmoderna del aburrimiento en el ocio -que se disfraza frente a una pantalla de televisión-, y a la imposibilidad de apropiarse de su trabajo para sí, como parte profunda de su ser, en una manera de "disfrazar" su miedo a la autonomía y a los riesgos de la libertad plena y realizadora que planteara Fromm en los siguientes términos:

Y no solamente se suprime directamente la hostilidad y se matan los sentimientos amistosos al sobre- ponerles su falsificación, sino que también hay una amplia gama de emociones espontáneas que son reprimidas y reemplazadas por seudosentimientos... Al aceptar esta norma, el individuo se ha debilitado grandemente; su pensamiento ha resultado empobrecido y achatado. Por otra parte, como las emociones no pueden ser por entero eliminadas, ellas han de mantener una existencia completamente separada del aspecto intelectual de la personalidad; el sentimiento barato e insincero que el cine y la música popular ofrecen a millones de sus clientes, hambrientos de emociones, resultan ser la consecuencia de todo esto. (Fromm, 1990, p. 281)

Así, el trabajo se da como una una imposición externa -odiosa y fatigante- presente cotidianamente y aceptada acríticamente para mantener la apariencia de felicidad medida por la cantidad de cachivaches tecnológicos acumulados en casa, por la cantidad de dinero -así sea aparente- y por la satisfacción de necesidades artificiales, necesarias para simular cierto sentido mezquino de felicidad, signado por la unidimensionalidad, en la que desaparece lo humanizante para significar de manera artificial y pasajera en la medida del fetiche que le da sentido.

Es el ser humano al servicio de los objetos, del consumo y de la ambición, en palabras de Marcuse (1990):

Una ausencia de libertad cómoda, suave, razonable y democrática, señal del progreso técnico, prevalece en la civilización industrial avanzada. ¿Qué podría ser realmente más racional que la supresión de la individualidad en el proceso de mecanización de actuaciones socialmente necesarias aunque dolorosas; que la 
concentración de empresas individuales en corporaciones más eficaces y productivas; que la regulación de la libre competencia entre sujetos económicos desigualmente provistos; que la reducción de prerrogativas y soberanías nacionales que impiden la organización internacional de los recursos? Que este orden tecnológico implique también una coordinación política e intelectual puede ser una evolución lamentable y, sin embargo, prometedora. (p. 31)

\section{Ocio y desarrollo humano}

La reflexión sobre el objeto del desarrollo económico no puede continuar siendo un diálogo entre distintas versiones de un mismo enfoque. A la hora de los hechos todas esas palabras se convierten en un monólogo, y todas las aparente contradicciones quedan resueltas en una misma equivocada convicción común: que el ocio es la causa principal de la pobreza, y que para salir de ella debe sacrificarse el presente, el hombre y la naturaleza. (Rodríguez Gómez, 1992, p. 25)

Acorde con este autor, el ocio alienado se fundamenta en un trabajo deshumanizado y desnaturalizado, a su vez, causa de la pobreza absoluta y relativa de la sociedad. Situación ésta que encuentra su origen en la valoración económica que mueve toda la vida cotidiana, es decir, la consecución, reproducción y acumulación de beneficios monetarios, sin más motivaciones ni posibilidades que la ganancia como último sentido de lo humano, y el dinero como el fetiche, el gran tótem, el único objeto de adoración, reverencia y culto.

Se ubica entonces el trabajo, en esa perspectiva, como el proceso que remedia la carencia de todo aquello necesario para una vida con las menores necesidades e incomodidades posibles; así que, en consecuencia, como un principio para la vida: trabaje duro, lo más duro posible y consuma sin límites o, en otro caso, si no quiere trabajar duro, rompa con la ley y con la decencia para que pueda seguir consumiendo, en esta segunda alternativa además es posible que se convierta en paradigma social y en héroe de seriados de televisión; en consecuencia, el trabajo se opone al ocio (por improductivo en cuanto al consumo) o, en otro caso, el ocio y el tiempo libre hacen parte del consumo mismo, un fetiche más.

En este proceso, el tiempo es uno de los bienes no renovables que se va consumiendo. En la medida en que el tiempo es irreversible y se agota en un proceso lineal se van cerrando las posibilidades de desarrollo por la degradación de la energía empleada para manejar y disponer del tiempo mismo, pues buena parte se agota en tiempo muerto (filas, transporte, etc.), otro en tiempo alienado (actividades laborales alienantes, exceso de televisión, uso inútil de redes sociales, consumo de sustancias destructivas, etc.), y mucho en actividades cargadas de estrés, nerviosismo y altos niveles de tensión. Por ejemplo, el agotamiento que depende de la velocidad con la cual la sociedad consume tiempo. Velocidad que mueve la dinámica de la producción: a más producción, más alta velocidad y viceversa, en un círculo vicioso que termina por consumir al ser humano.

A su vez, esta concepción del tiempo para la realización humana se forma en la interacción de la ética del trabajo, el control del tiempo y la racionalidad económica.

La ética del trabajo desarrollada desde los inicios del capitalismo convirtió lentamente al trabajo en el valor moral que da sentido a la vida y su única fuente de realización, centrada siempre (en mayor o menor medida) en la oportunidad, el éxito y el pragmatismo (incluso teorías críticas como el marxismo mantienen el mismo principio). Por su parte, el control del tiempo se asimiló como 
control social por las vías coercitiva y cohesiva: o "aprovecha el tiempo" produciendo o pierde la vida en el ocio y en los sueños improductivos. La racionalidad económica, que busca maximizar la tasa de ganancia, encuentra necesariamente en el tiempo el punto de referencia que ratifica o niega la efectividad del proceso de valoración del capital, por eso hizo carrera rápidamente desde el siglo XIX la frase de Edward George BulwerLytton (atribuida comúnmente a Benjamín Franklin): "el tiempo es oro".

La combinación de esas tres características en el capitalismo conduce a asignar al tiempo de trabajo la función de ser el ámbito de la realización y de la mayor ocupación porque lo productivo es aquello que al generar ingresos monetarios realiza al ser humano en la medida de su capacidad de consumo. Cualquier otra actividad susceptible de ser realizada en el tiempo es considerada sólo en función de sus efectos sobre el trabajo. La recreación es, precisamente, la recuperación del desgaste causado por el trabajo para poder volver a emplear la fuerza de trabajo. De ahí los límites entre los que fluctúa la jornada de trabajo: un mínimo tal que permita la existencia de tiempo de trabajo excedente y por tanto de plusvalía con una tasa de ganancia media; un máximo tal que la fuerza de trabajo sea recuperable.

Se vive desde el drama de la educación hasta el otro drama, el de la jubilación: Desde la educación infantil, el ser humano aprende a no "perder tiempo" y aprovecharlo en tareas y trabajos lo más farragosos y pesados posibles para que adquiera sentido del sacrificio y del esfuerzo y no pierda el tiempo; las actividades lúdicas y recreativas son una especie de "agregado" al margen. Por eso en la jubilación, las personas también viven el drama de "no tener nada qué hacer" o sea, no producir en la vida laboral.

A manera de ejemplo: a mayor velocidad y potencia de nuestros automóviles contradictoriamente disminuye la movilidad y el desplazamiento se hace más lento, a tal punto que hoy en día la movilidad urbana es inmensamente más ruidosa, más histérica y más contaminante, pero no hay mayor valor agregado que compense semejante costo si se compara con la velocidad de desplazamiento urbano de los tiempos de las carretas y de los caballos; igual ocurre con el trabajo: a mayor tecnología y capacidad, el tiempo de trabajo no disminuye ni se hace más grato, al contrario: más tiempo se dedica al trabajo (o a los trabajos), más estrés, neurosis y enfermedades produce y más vida laboral invade la vida familiar. Esta es una trampa del internet y los sistemas virtuales en la que caemos con frecuencia: en el siglo XXI se "vive" en el trabajo, en la vida laboral, las 24 horas del día, sin respeto por ningún otro tipo de espacio. Es muy factible ver a una persona dedicando parte (jo todo!) su tiempo familiar al trabajo mediante medios virtuales. Nadie va con sus hijos al trabajo, pero comúnmente vamos con nuestro trabajo a donde nuestros hijos.

Con el desarrollo del capitalismo la duración del trabajo ha venido modificándose debido al progreso en las fuerzas productivas de la sociedad y a la ampliación de su capacidad tecnológica. Esa situación ha hecho que en las sociedades de clases, en teoría, la disponibilidad de tiempo libre vaya aumentando. Sin embargo, llegado a un punto el tiempo libre empieza a disminuir por la presencia de tiempos vacíos (o tiempos muertos), como el tiempo de transporte; igualmente, tendencias recientes muestran que, al contrario, el tiempo dedicado al trabajo va en aumento. En sociedades anteriores (por ejemplo, las indígenas), la disponibilidad de tiempo libre era mucho mayor $\mathrm{y}$, aún más, cualitativamente era mucho más gratificante y significativo. Además, la sola reducción en la jornada de trabajo no garantiza ningún avance en el establecimiento de unas relaciones de producción fundadas en la autonomía, la creatividad y el bienestar individual, pues el ocio y sus actividades pueden terminar siendo un fetiche más para el consumo y para la deshumanización. 
Toda referencia al trabajo (cuyo concepto se refuerza como "trabajo productivo") en el capitalismo busca oponerlo al ocio ("tiempo improductivo"), y por ese camino se termina reprobando al ocio en sí mismo, a no ser como un premio a la fatiga del trabajo o una recarga de fuerzas para soportar más trabajo, pero el tiempo de ocio por sí mismo no cuenta. El trabajo, visto por ese camino como el extremo opuesto del ocio, es elevado al nivel de fuente única de bienestar social y de realización personal, como si fuera una antropología del trabajo, con una ontología legitimadora alrededor del éxito, porque ese es el supuesto sentido de la vida, de su realización:

Muchas cargas pesadas hay para el espíritu; para el espíritu paciente y vigoroso en quien domina el respeto. Si vigor reclama la carga pesada, la más pesada. El espíritu robusto pregunta: ¿qué hay de más peso? y se arrodilla como el camello y quiere una buena carga. ¿Qué hay de más pesado? -Pregunta el espíritu robusto-. Dilo ¡oh héroe!, a fin de que cargue con ello sobre mí y mi fuerza se alegre. ¿Acaso esto no es humillarse para hacer sufrir a su orgullo, hacer brillar su locura para cambiar en amarga burla su sabiduría?... (Nietzsche, 1985, p. 52)

Pero, en otra perspectiva, el ocio no es lo contrario del trabajo. El ocio puede ser trabajo y, simultáneamente, el trabajo puede ser ocio, en una actividad situada más allá de la presión del tiempo. Esto es lo que permite ver la realidad de la ideología de la economía del trabajo al ocultar la posibilidad de que el ser humano viva sin la presión del tiempo y las necesidades artificiales generadas por la exacerbación del consumo, en el ejercicio autónomo de sus actividades; pues al fin y al cabo es el consumo artificioso y desaforado la verdadera motivación que se esconde detrás de la legitimación del trabajo arduo (ojalá dos o tres trabajos al tiempo) como la mayor satisfacción del ser humano consigo mismo.

El tiempo libre, por el contrario, sí es lo opuesto al trabajo. El ocio puede ser aislado del trabajo, si es basado en la ausencia de premura en cualquier actividad a partir de la inversión del sentido del tiempo al ponerlo servicio del ser humano. Desaparece la diferencia entre lo activo y lo pasivo. El ocio permite entonces el libre desarrollo de la creatividad, el sentido esencial de la libertad y la comprensión de la existencia humana.

Desde el punto de vista de la transformación de la energía, el ocio detiene el proceso entrópico. Es el no consumo de energía ni de tiempo y, por tanto, la ampliación del presente. Es haber vivido, vivir y prepararse para vivir, en una interacción permanente de aprendizajes, desaprendizajes y reaprendizajes.

Al contrario, en el desarrollo económico colombiano la crítica al ocio ha sido un hecho permanente. Su origen se encuentra en el largo proceso de formación de la ideología del trabajo, consustancial al desarrollo capitalista. Las ideas de muchos de los pensadores sociales se han encaminado a una sustentación del trabajo como solución para el desarrollo nacional. Igualmente, estos pensadores ven como un símbolo de subdesarrollo y atraso la existencia de muchos días feriados, mientras hacen panegíricos de otras sociedades con menos festivos y menos tiempo libre, como si dar menos descanso a las personas las hiciera mejores. Además, en estas sociedades con menos días libres las jornadas semanales de trabajo son inferiores. Cuando algunos de ellos han hecho referencia a la necesidad de descanso y recreación, simplemente han reforzado el ideal del trabajo. Para que éste no se agote y rinda más han encontrado algún valor en el descanso.

Más de cien años de desarrollo industrial y urbanización del país no se han visto correspondidos con reducciones notorias de la jornada laboral, 
mucho menos con la posibilidad de que surja cualquier alternativa de recuperación del ocio. Se han confundido tanto el trabajo como el ocio con el tiempo propio del desarrollo del capital que "aprovechar el tiempo" trabajando se ha convertido en la máxima señal de realización humana.

Como principio para un desarrollo alternativo debe ser tenida en cuenta la resignificación del ocio, su descentramiento del trabajo para que sea fuente autónoma de bienestar social. Eso es lo que debe ser, y en cierta forma es utópico, pero la utopía es un llamado que impulsa lo que se debe hacer para que sea realizado. Es la apertura de nuevas posibilidades en un mundo que restringe cualquier capacidad creativa. La reivindicación del ocio es la reivindicación de lo humano y de lo natural; pero, por el contrario, se va haciendo dramáticamente cercana y visible la sociedad "feliz" de Huxley (1979):

-La población óptima -dijo Mustafá Mond- es como el iceberg. Ocho novenos bajo el agua y uno encima.

- ¿Y son felices bajo el agua?

-Más felices que encima. Más felices que sus amigos, por ejemplo- y los señaló con el índice.

- ¿A pesar de su odioso trabajo?

¿Odioso? No lo creen ellos así. Al contrario, les gusta. Es leve y de una simplicidad infantil. No agota la mente ni los músculos. Siete horas y media de un trabajo leve y muy llevadero y luego la ración de soma, y deportes sin trabas y el cine sensible. ¿Qué más pueden pedir? Cierto -agregó- que pueden pedir menos horas y desde luego podríamos concedérselas. Técnicamente, sería sencillísimo reducir el trabajo de las castas inferiores a tres o cuatro horas al día. Pero, ¿serían más felices por ello? De ningún modo. Ya se hizo el experimento, hace más de siglo y medio. Irlanda entera se organizó sobre la base de cuatro horas al día. ¿Cuál fue el resultado? Revueltas y un aumento en el consumo de soma; nada más. Estas tres horas y media suplementarias de ocio estaban tan lejos de ser un manantial de dicha, que las gentes véanse obligadas a procurarse vacaciones para huir de ellas. La oficina de inventos rebosaba de planos de procedimientos para economizar trabajo: a millares...

-Mustafá hizo un amplio ademán-. Y, ¿por qué no los realizamos? Por el bien de los trabajadores; sería pura crueldad el afligirlos con un excesivo ocio. Lo mismo ocurre con la agricultura. Podríamos reducir por síntesis hasta el último bocado de nuestros alimentos, si quisiéramos. Pero no lo hacemos. Preferimos que un tercio de la población se dedique a los trabajos de la tierra. Y esto en su propio beneficio. Solo porque cuesta más tiempo obtener el alimento de la tierra que el que da una fábrica. Además hemos de pensar en nuestra estabilidad. No queremos cambiar. Cada cambio es una amenaza a la estabilidad. Esta es otra razón por la que estamos tan poco inclinados a aplicar invenciones nuevas. Cada descubrimiento de la ciencia pura es potencialmente subversivo; hasta la ciencia ha de ser tratada como un posible enemigo. Sí, hasta la ciencia. (p. 208)

Se necesitan nuevos modos de realización que corresponda a las nuevas capacidades, contenidos y modalidades de la sociedad del siglo XXI, que resignifique y de sentido a una modernidad en permanente licuefacción de sus ideales, valores, creencias y sentidos de solidaridad. En el planteamiento de Bauman (1999), como "modernidad líquida", la indagación por la identidad es el compromiso vital de la persona, y este empeño de construirse a sí mismo es la última posibilidad de arraigo, de identidad, que nos queda. Así, 
en la modernidad líquida las identidades son semejantes a una capa volcánica que se endurece, vuelve a disolverse y cambia incesantemente de forma. Éstas parecen inalterables desde un punto de vista externo, pero, al ser contempladas por el mismo sujeto, brota la inconsistencia y el desgarro constantes. Por este proceso el individuo debe trasegar para poder integrarse a una sociedad cada vez más global, pero sin identidad fija, y sí, maleable, voluble. Es decir, buscar su identidad en aquello que, de por sí, no tiene una identidad consistente. Pero, a la vez, esta identidad resbalosa, fangosa, nos hace cada vez más dependientes del otro y es ahí donde se encuentra la esperanza de crear condiciones de crecimiento en términos de humanidad, conciencia social por el bien individual a partir de lo común en armonía con la naturaleza, en una nueva dimensión del trabajo y del ocio que trascienda lo meramente productivo en la medida de la vida como una vida al servicio de sí misma no de los fetiches que la alienan, la suplantan o la simulan.

\section{Tiempo libre: ¿utopía o realidad?}

Con lo expresado hasta aquí, acorde con la propuesta analítica de Kellman y Fernández (1986), aparece la necesidad de preguntarse por lo que podría ser su proyección en un futuro. Las visiones sobre el tiempo libre indefectiblemente hacen referencia a este aspecto. Si bien las utopías se han presentado a través de la historia de manera tan lejana de la más humana y cotidiana realidad que se les ha calificado de irrealizables, ellas le plantean a la sociedad una situación dilemática o una dinámica de búsqueda incesante. "las utopías son realizables. La vida marcha hacia las utopías. Y puede ser que comience un siglo nuevo, un siglo donde los intelectuales y la clase cultivada soñarán con los medios de evitar las utopías y de retornar a una sociedad no utópica, menos "perfecta" y más libre" (Berdaiev, 1979, p. 28).

Por ejemplo, Huxley (1979) plantea la posibilidad de un mundo feliz, proyectando de manera irónica las esperanzas de quienes siguen creyen- do en el milagro de una sociedad de consumo cómoda y sin limitaciones, con todo prefabricado, hasta las mismas realizaciones humanas. Su obra lleva implícita, no solo una cáustica crítica a la felicidad del consumo, la abundancia y el facilismo que permiten un cómodo control total de la sociedad, sino también un llamado angustioso a buscar otras alternativas frente a esa aplastante realidad del hipermercado mundial histéricamente consumista y discriminatorio hasta la más indigna vileza. "Imaginaos qué tontería es permitir a la gente jugar a juegos complicados que en ninguna manera aumentan el consumo. Es una locura. Hoy en día los inspectores aceptan solo los juegos nuevos, que requieren cuando menos, tantos accesorios como el más complicado de los existentes..." (p. 951).

No muy lejos del gusto estandarizado, de la filosofía del regalo como expresión de pseudoafectos espontáneos e inmediatistas (los días comerciales de todo y para todas las celebraciones), los mensajes educativos del mundo feliz plantearían cuestiones como estas: "En las salas de los niños, terminaba la lección de concepto elemental de las clases sociales; las voces adaptaban la futura demanda a la futura oferta industrial. "Cómo me gusta ir en avión ¡-susurraban-, ¡cómo me gusta ir en avión!”, “¡me gusta estrenar un traje, cuánto me gusta...!" "Los trajes viejos son horribles -continuaba el infatigable murmullo- Hay que tirarlos!" "Vale más desechar que tener que remendar; vale más..." "Cuanto más remiendo, más pobre me siento” (p. 966).

La curiosa contradicción: el "tiempo libre" está totalmente programado y plagado de actividades perfectamente planificadas por los mass-media, por el turismo, por los centros comerciales, etc., de tal manera que es imposible imaginar el ocio no programado como recreación para la realización humano sino sólo como una sutil, dulce y cómoda alienación.

"Hoy en día -he aquí el progresolos viejos trabajan y no tienen tiem- 
po que perder; ni un momento para sentarse a pensar; y si, por cualquier malhadada circunstancia, el tiempo produjese una grieta en la masa compacta de sus distracciones, queda el soma, el delicioso soma, del que medio gramo equivale a medio día de descanso, un gramo a un fin de semana, dos o una escapada por el Oriente Magnífico, tres a una sombría eternidad en la luna; y al retorno, se hallan al otro lado de la grieta, sanos y salvos en la tierra firme de los trabajos y diversiones cotidianas, corriendo de cine-sensible, de chica en chica-neumática, de campo en campo de golf electromagnético". (p. 972)

En esta misma medida, el ocio en una sociedad potencialmente redimida del tiempo de trabajo del control social y de la programación del tiempo del individuo, son presentados: "Siete horas y media de un trabajo leve y muy llevadero, luego la ración de soma, y deportes sin trabas y el cine sensible. ¿Qué más pueden pedir? (...) Técnicamente sería sencillísimo reducir el trabajo de las castas inferiores a tres o cuatro horas al día. Pero, ¿serían más felices por ello? De ningún modo. Ya se hizo el experimento (...) ¿Cuál fue el resultado? Revueltas y aun aumento en el consumo de soma; nada más" (p. 1110).

Las anteriores reflexiones, que expresan ciertas realidades del uso del tiempo libre en la actualidad, confirman la necesidad apremiante de una crítica objetiva al ocio burgués, al sentido del tiempo y al esquema capitalista que lo fundamenta. Se requiere pensar en un nuevo modelo de sociedad en la cual el ocio, practicado con libertad, conduzca a la verdadera dimensión del tiempo libre. (Kellman \& Fernández, 1986).

En este sentido, como lo plantea Munné (1980), eliminar la alienación supone una liberación global, lo cual depende no solo del tiempo de ocio sino también del restante tiempo social. La pro- blemática se sitúa a un nivel superior sobre la crítica al tiempo libre, por cuanto involucra las estructuras económicas y políticas. Sin embargo, se deben entablar acciones inmediatas que estarían orientadas a una ampliación y formación de un pensamiento crítico y, de manera más concreta, a la búsqueda de una reducción del consumo en lo que tiene de manipulado y alienante. De esta manera, "podremos reducir -ya que no eliminarla producción en lo que ésta tiene de alienante. Hay que crear un nuevo tiempo liberador, que posibilite la contrafunción del ocio en relación consigo mismo y deje de ser el primer enemigo del tiempo libre. Es entonces cuando podrá asomar su cabeza, por entre el ocio y el trabajo. El tiempo libre" (Munné, 1980, p. 160).

No se pretende construir todo un nuevo modelo social en el espacio de un ensayo, ni cómo ha de ser utilizado el tiempo libre en ese potencial proyecto liberador; pero sí considerar que en una nueva sociedad podrían existir más posibilidades para que sus integrantes hagan uso adecuado y humanizante del tiempo libre en condiciones de libertad. "Porque lo que el tiempo libre ha de ser, en un nuevo tipo histórico de ocio, sólo el hombre liberado debe decidirlo y puede crearlo" (Munné, 1980, p. 175).

\section{DISCUSIÓN}

\section{Sentido liberador de la recreación: alteridad lúdica}

"Derivado del verbo latino lúdere, que significa jugar, el término lúdico se refiere al juego como recreación y como re-creación. La vida humana no se termina en el trabajo, ni es toda ella el serio y desgastador cumplimiento de deberes. Es también descanso, distracción, juego, diversión. Todo esto es actividad, y actividad buena y necesaria como el mismo trabajo. Pero también en ella se en- 
cierra el peligro de la alienación; una alienación que, a diferencia del trabajo, resulta sutil y placentera. Ya los políticos romanos sabían que con pan y circo se podía tener satisfecho a un pueblo.

El sistema totalizante utiliza la diversión y el juego como distractivos de las contradicciones internas que amenazan con introducir la exterioridad y agrietar el orden de la mismidad. Todos somos testigos del poder de un campeonato mundial de fútbol como tranquilizante nacional o internacional. Los problemas sociales, laborales, familiares, políticos desaparecen como por arte de magia. Una buena fiesta, un campeonato animado, un espectáculo triunfalista son capaces de mantener sosegados y contentos a los estudiantes en la universidad, a los obreros en la fábrica, a los campesinos en sus parcelas. De este modo el ocio sano y conveniente se convierte en opio de conciencias individuales y colectivas". (González Álvarez, 1996, p. 61)

La alteridad hace referencia a las distintas maneras de relacionarse con otros seres humanos y con la naturaleza en el contexto de la dignidad, del reconocimiento y del respeto. Está referida a las habilidades de auto-reconocimiento (autoestima y autoimagen), a las habilidades alteritativas dadas desde el sentido de la otredad como reconocimiento del otro en cuanto otro, y a las habilidades ecológicas de reconocimiento de la naturaleza como fuente única de la vida. Así pasamos de un yo cerrado a un yo abierto, lo que hace que la reflexión humanística no empiece en el Yo, sino en el Otro. Entonces ¿Cuándo soy yo? Cuando otro me nombra, otro identifica mi rostro y yo identifico el rostro del otro, pues "el rostro es lo que nos prohíbe matar". El "pienso, luego existo" cartesiano da paso al: "soy reconocido, soy nombrado, luego soy". Así: "Desde el mo- mento en que el otro me mira, yo soy responsable de él sin ni siquiera tener que tomar responsabilidades en relación con él; su responsabilidad me incumbe. Es una responsabilidad que va más allá de lo que yo hago" (Levinás, 2000, p. 80).

Es entonces la resignificación del sentido de la virtud como construcción humanizante, como posibilitación de todas las maravillosas riquezas materiales, espirituales, psicológicas, afectivas e intelectuales que pueden generar cierto sentido integral de la realización humana en torno a la calidad de vida como camino y la excelencia como meta (meta como punto del camino en el que se abren múltiples y enriquecedoras posibilidades). Este sentido de virtud, como virtud pública, podría describirse en la medida de:

"la exaltación de la persona virtuosa, que corresponde al profundo y radical compromiso sociopolítico del ser humano en su autonomía; en el mismo sentido que, siglos después de la vida del Santo (Santo Tomás), otro filósofo la definiera como "la liberación del hombre de su culpable incapacidad. ¡Sapere aude! Ten el valor de servirte de tu propia razón sin la guía de otro" (Kant, 1992, p. 5) o como Aristóteles, citando a Hesíodo, la define: "El varón superior es el que por sí lo sabe todo; bueno es también el que cree al que habla juiciosamente; pero del que ni suyo sabe ni deposita en su ánimo lo que oye de otro, es un tipo inservible". (Aristóteles, 1982, p. 27) Principios en los que el fundamento de la virtud misma se inicia necesariamente con este sentido de autonomía como responsabilidad y autoafirmación de la utopía del equilibrio entre la libertad y la justicia". (Acebedo Afanador, 1995, p. 37)

En este marco, usualmente los seres humanos desarrollan dos tipos de actividades en su vida 
cotidiana: actividades trabajosas ("cumplir con el deber": carga pesada y fatigosa pero necesaria) y actividades felicitarias -o supuestamente felicitarias- (camino, encuentro y desarrollo de la realización plena del ser humano en el tiempo libre). Pero contradictoriamente la realización se pone en manos de la parte difícil y pesada, en la que "se cumple el deber". De esta forma, los seres humanos no pueden desprenderse de las actividades trabajosas, son su sino cruel, su fatal carga cotidiana. El cumplimiento del deber, signado por el sacrificio, el silencio, la pequeña venta cotidiana de la conciencia, y la monotonía, se hace paradigma de estabilidad personal y social, además de símbolo de prestigio y de "tranquilidad" individual.

La recreación generalmente se asigna al tiempo libre de las personas, entendido éste último como el sobrante, luego de la jornada laboral productiva en términos económicos. Esta concepción del tiempo libre es mezquina y empobrecedora en lo que se refiere a la recreación, pues, en esta acepción, ésta última implica culturalmente "el momento feliz" mientras que el trabajo se convierte en la pesada carga cotidiana.

Así las personas terminan llevando una curiosa vida en la que le dedican toda su energía a actividades económicamente productivas, pero que no los realizan como seres humanos. Es otra de las tantas contradicciones del capitalismo: trabajar duro la mayor parte del tiempo para disfrutar e intentar ser feliz (o al menos simular felicidad) en la franja más pequeña, al final del día y en el fin de semana. En este espacio de tiempo más pequeño se "disfruta" viendo televisión, durmiendo, en redes sociales, en juegos virtuales o, simplemente, sin hacer nada. Algunas actividades constructivas (física o espiritualmente) oscilan con frecuencia entre lo muy, pero muy ocasional y el nunca: el cine-arte, el libro, el teatro, el deporte, el cultivo de aficiones creativas, etc., y ni para qué hablar de actividades de carácter comunitario, político, social, etc. Su escasa práctica no es simplemente producto de la situación eco- nómica particular, pues las clases medias y altas actúan de manera similar en este aspecto.

En este sentido, la esclavitud del consumo, por exceso o por defecto, incluye la esclavitud del trabajo como ocupación necesaria pero alienante y del ocio como forma de aquietar el espíritu en la abulia cultural de la pasividad y la heteronomía propiciada y mantenida por los medios masivos de información y manipulación social o por el ocio programado. La persona conforme, resignada y aburrida -el ciudadano obediente y acrítico-, trabaja sin protestar, consume más y no genera problemas ni cuestionamientos al sistema que lo somete a tal vida.

El ser humano hoy día no se entretiene, se aburre de tal manera que el aburrimiento pasa a ser parte normal del ocio, en un sopor invencible que adormila sus maravillosas fuerzas creativas para recibir hecha -prefabricada $y$, a la vez, desechable- su recreación, en un mundo de ilusiones y sensaciones programadas donde todo parece ser pero no es.

Hace falta innovación, imaginación, creatividad y capacidad de riesgo, como fundamentos de suyo esenciales, para buscar un renovado sentido trascendente y propiamente humano de la recreación, para vencer el sentido fatalista de la cultura del ocio como una parte subyacente de la monotonía cotidiana del consumo.

En esta perspectiva, una nueva pedagogía de la recreación se impone como necesaria alternativa a la aburrida tradición y a las novedades alienantes. Es cosa de cada uno imaginar cómo, poner el consumo, de manera crítica, al servicio racional del ser humano y proponer alternativas que permitan un modo de la felicidad que no se determine por la obligación del deber ni por las ilusiones programadas ni por el consumo desaforado ni por la recreación prefabricado, sino que, sencillamente, se funde en la libertad del tiempo, con todas sus maravillas y posibilidades, para el ser humano. 


\section{REFERENCIAS BIBLIOGRÁFICAS}

Acebedo Afanador, M. J. (1995). Ser o Comprar: entre la virtud y la competencia. Temas, 1(2). Aristóteles. (1982). Ética Nicomaquea. Medellín: Bedout.

Baumann, Z. (1999). Modernidad líquida. Buenos Aires: Fondo de Cultura Económica.

Berdaiev, N. (1979). El Sentido de la historia: experiencia de la filosofía del destino humano. (E. Saura, Trad.) Barcelona: Encuentro.

Calvino, I. (2000). Las ciudades invisibles. (A. Bernárdez, Trad.) Madrid: Siruela.

Fromm, E. (1990). El miedo a la libertad. (G. Germani, Trad.) Buenos Aires: Paidós.

González Álvarez, L. (1996). Ética Latinoamericana. Bogotá: Universidad Santo Tomás.

Huxley, A. (1979). Un mundo feliz. Barcelona. Plaza y Janés. Barcelona: Plaza y janés.

Kant, E. (1992). ¿Qué es la ilustración? En E. Kant, Filosofía de la Historia. Bogotá : Fondo de Cultura Económica.
Kellman, T. \& Fernández A. C. (1986). Tiempo libre turismo y Sociedad. Bogotá: Universidad Externado de Colombia.

Levinás, E. (2000). Ética e infinito. Madrid: Machado Libros.

Marcuse, H. (1990). El Hombre Unidimensional. Barcelona: Ariel, 2ed., 1990. Págs. (2 ed.). Barcelona: Ariel.

Marx, C. (2005). Manuscritos Económicofilosóficos de 1844. Recuperado el 4 de junio de 2013, de Marxistas.org: http://www.marxists. org/espanol/m-e/1840s/manuscritos/man1.htm Munné, F. (1980). Psicosociología del tiempo libre: Un enfoque crítico. México: Trillas.

Nietzsche, F. (1985). Asi hablaba Zarathustra. Madrid: Edaf.

Rodríguez Gómez, J. (1992). Tiempo y ocio. Bogotá D.C: Universidad Externado de Colombia. 